As well as having these direct ill-effects, the acids can also cause damage indirectly. For example, acid rain leaches aluminium from some soils which then runs into lakes and streams, where it can be highly toxic. Similarly, such heavy-metals as mercury, cadmium, manganese, and lead, are rendered far more toxic by acid than neutral or basic water. Acidity encourages the formation of compounds in which organic molecules and heavy-metals have combined chemically, producing substances which are highly toxic to most forms of aquatic life. As the most sensitive creatures die, so do other life-forms which depend on them for food. In the end the whole ecology of the lake is altered.

Acid precipitation also produces direct ill-effects on buildings and other structures the railway lines in the Katowice area of Poland have become so corroded by it that strict speed-limits have to be enforced. Stone buildings eventually begin to crumble and disintegrate, and paint-work blisters. The economic effects of the corrosion caused by sulphur and nitrogen oxides have been estimated at thousands of millions of dollars a year.

The effects on forestry are more controversial, and in spite of many studies scientists do not agree on exactly how acid rain affects forests. However, the role of aluminium and heavy-metals is suspected. In addition, acid rain may damage forests by leaching out other metals, such as magnesium and calcium, which are essential for forest growth.

Finally, acidity brought in precipitation is beginning to percolate through to ground-water reserves. Thus for example a survey on Sweden's west coast recently found that $49 \%$ of drinking wells were acidic--causing corrosion in pipes, foul-tasting water, and diarrhoea.

The acid precipitation situation is already critical in several respects and, as more and more countries turn to increased uses of coal for electricity production, there is a very real danger that things could worsen drastically. Only energy conservation and the application of known sulphur-pollution prevention technologies at new coalfired power-stations seem likely to prevent acid rain from becoming a major ecological catastrophe.

PaUl EVAN REss*
Senior Regional Information Officer
United Nations Environment Programme
Palais des Nations
1211 Geneva 10
Switzerland.

\section{Winston Churchill Travelling Fellowships}

Next year about one hundred fortunate people will be given the opportunity to travel almost anywhere in the world they may wish. They will have to prove that their work and interests could benefit from experience overseas, and that also in other respects they would be suitable for the award of a Winston Churchill Travelling Fellowship.

There are no particular educational or professional qualifications needed for application, no age restrictions,

\footnotetext{
*Now retired and living at 19 Avenue du Budé, 1211 Geneva, Switzerland.-Ed.
}

and all UK citizens are equally eligible. Churchill Fellows do, however, have to indicate how they propose to make use of their knowledge for the benefit of others on their return to the United Kingdom. The categories in which awards are offered for 1983 include emergency services of various kinds, natural history and conservation of local environment, and sewage, water, and flood-control, workers.

If you would like an application form and explanatory leaflet, just send your name and address on a postcard to:

\author{
Winston Churchill Memorial Trust \\ 15 Queen's Gate Terrace \\ London SW7 5PR, England, UK.
}

\section{The Journal of Arid Environments}

A forum for multidisciplinary dialogue in the fields indicated by its title, the Journal of Arid Environments (published by Academic Press, London, England, UK) was launched in 1978 to provide an outlet for the publication of original scientific and technological research and, simultaneously, to publish comprehensive reviews that should be intelligible to advanced students, technologists, administrators, and research workers, whatever their specializations and disciplines.

There is no single answer to the problems of the arid regions: these result mainly from increasing human populations, overgrazing by domestic stock, salinization, the felling of trees for firewood, and soil erosion. The wisest solutions vary according to local circumstances, including the cultural and religious attitudes of the indigenous peoples. Although science may point the way in which development can best proceed, administrators often have little idea either of the knowledge currently available or of how to apply it. The Journal provides an authoritative work of reference presenting new ideas, scientific facts, and guidance in how to apply them. Book reviews and technical notes increase the number of topics covered, and help to maintain a broad approach.

The ecosystems of arid environments are fragile and vulnerable to misuse. Social and geographical studies are, therefore, of more than mere academic interest. They illustrate the causes of desert expansion and indicate ways in which arid zones may be developed for the benefit of their inhabitants without engendering environmental deterioration. The solutions to social and economic problems can sometimes be simpler than is generally realized. For instance, one recent article drew attention to the fact that it might be more profitable to invest resources in the production of better-quality stock, which would be able to withstand a heavy trypanosome infection, than to spend the same amount of money and effort in attempting to achieve improved control of tsetse-flies (Glossina spp.), vectors of African sleepingsickness and 'nagana' of horses and cattle.

Other recent contributions outline methods of managing finite groundwater supplies, or deal with Islamic water laws and oasis settlement, nomadism and pasturalism, wildlife conservation and land-use, the production of energy from salt and from solar radiation, weather modification, and remote-sensing from satellites.

The world's arid biomes are among the most inhospitable of all terrestrial environments. The adaptations of 
their floras and faunas provide fascinating topics for biological research, and numerous papers are devoted to various aspects of plant and animal physiology and ecology. Desert soils, geomorphology, and climate, likewise claim their share of the research papers and review articles. The Journal is well printed, lavishly illustrated, and each volume is provided with comprehensive indexes. It is subscribed to by leading libraries and institutions throughout the world.

\section{John L. Cloudsley-Thompson Editor \\ The Journal of Arid Environments c/o Department of Zoology \\ Birkbeck College (University of London) \\ Malet Street \\ London WCIE 7 HX \\ England, $U K$.}

\section{Northernmost Land on Earth?}

The most northerly point on the mainland of Greenland is Kap Morris Jessup $\left(83^{\circ} 39^{\prime} \mathrm{N}\right.$.) and until recently it was thought to be the most northerly point of land in the world. Danish geophysicists, however, have now determined that a tiny island, most often hidden by sea-ice, must be considered the most northerly land. The placename committee for Greenland has decided that this island be named after the Polar Eskimo Otaq, from Thule, who 'drove' Peary's sled on his North Pole expedition in 1909.

It should be pointed out that Otaq's Island is not recommended as a tourist spot, say the editors of the newssheet published by the Danish Arktisk Institutas quoted in Information North, newsletter of the Arctic Institute of North America, which is now housed at the University of Calgary, 11th Floor Library Tower, 2500 University Tower NW, Calgary, Alberta T2N IN4, Canada.

\section{The International Foundation for Science}

Founded in 1972, the International Foundation for Science (IFS) is a nongovernmental organization with a membership of 65 scientific academies and research councils in 58 countries, of which two-thirds are in developing countries and one-third in industrial countries. The Foundation is governed by an international Board of Trustees, with the Secretariat located at Sibyllegatan 47, S-114 42 Stockholm, Sweden.

The Foundation provides young scientists and technologists of outstanding merit from developing countries with financial and other support in their work. Criteria for a grant are the scientific quality and potential of the proposed research project and its relevance to the needs of the country.

- Grantees must be native to, and carry out the research in, a Third World country.

-The IFS currently supports research in the fields of applied biology, agriculture, and rural technology (see below).

- The grants enable research workers to purchase special equipment and expendable supplies. Normally, the grants are limited to the amount of US $\$ 10,000$ per period, for not more than four periods.

- The communication and sharing of scientific information between the grantees themselves and between grantees and senior advisers, is encouraged and promoted by regional meetings and visits to project sites. - Research is conducted in 69 countries in Asia, Africa, Oceania, and Latin America.

-There were 578 grants awarded between 1974 and January 1982.

At present eleven countries, and UNESCO, contribute to the Foundation's budget-normally by government grants made through academies or research councils. The budget for 1981 was slightly more than two million United States dollars. The institutes of the grantees contribute the grantees' salaries and basic support for their research - often with amounts that are several times as high as the Foundation's grants.

The present scientific areas of interest and support are the following:

1) Aquaculture:-Research on fish and shellfish to develop local fish-farming; fry production, including artificial spawning; feeding, genetic improvement, cultivation techniques; useful aquatic plants.

2) Animal production:-Development of new feed-resources and methods for dry-season feeding; introduction of improved animal production systems, with research on neglected animal species and collection of basic information on performance of local breeds; prolonging storage-life of animal products.

3) Vegetables, oil-seeds, and fruits:-Crops of value particularly in subsistance agriculture; research on plant physiology and pathology; genetic improvement for higher yield and disease-resistance; cultivation techniques, disease control, and drought resistance; plant-soil-water relationships, soil microbiology; methods for improved storage and simple processing.

4) Mycorrhiza and afforestation:-Symbioses between Fungi and roots of trees or agricultural plants; research in physiology, ecology, and symbiotic efficiency, of different Fungi; inoculation methods; reafforestation methods for tropical countries.

5) Fermentation and applied microbiology:-Traditional fermentation processes, research on mycotoxins; new methods for food preparation; storage of food; biogas.

6) Natural products:-Utilization, isolation, and investigation, of useful compounds from plants; search for new sources of plant-derived chemicals; structure elucidation; phytochemical and pharmacological investigations, including ethnobotanic studies; cultivation.

7) Rural technology:- Low-cost technology for rural and agricultural construction, particularly with locally-available materials; examples from fish-ponds, human dwellings, animal housing, drying and storage facilities, small-scale energy plants for villages or farms, and water systems.

At present, 58 countries have IFS member organizations.

GORDON C. BUTLER
President
International Foundation for Science
c/o National Research Council
Sussex Drive
Ottawa
Ontario KIA OR6
Canada.

